\title{
Mesenchymal Stem Cell-Based Therapy for Lysosomal Storage Diseases and Other Neurodegenerative Disorders
}

\author{
Shaza S. Issa ${ }^{1,2}$, Alisa A. Shaimardanova ${ }^{1}$, Victor V. Valiullin ${ }^{3}$, Albert A. Rizvanov ${ }^{1 *}$ and \\ Valeriya V. Solovyeva ${ }^{1}$
}

${ }^{1}$ Institute of Fundamental Medicine and Biology, Kazan Federal University, Kazan, Russia, ${ }^{2}$ Faculty of Biology, Saint Petersburg State University, Saint Petersburg, Russia, ${ }^{3}$ Department of Histology, Cytology and Embryology, Kazan State Medical University, Kazan, Russia

\section{OPEN ACCESS}

Edited by: Igor Lavrov,

Mayo Clinic, United States

Reviewed by:

Irina Zaidman,

Hadassah Medical Center, Israe Marina Khodanovich,

Tomsk State University, Russia

*Correspondence:

Albert A. Rizvanov

rizvanov@gmail.com

Specialty section: This article was submitted to

Neuropharmacology,

a section of the journal

Frontiers in Pharmacology

Received: 21 January 2022 Accepted: 17 February 2022

Published: 02 March 2022

Citation:

Issa SS, Shaimardanova AA, Valiullin W, Rizvanov $A A$ and Solovyeva W (2022) Mesenchymal

Stem Cell-Based Therapy for Lysosomal Storage Diseases and Other Neurodegenerative Disorders.

Front. Pharmacol. 13:859516. doi: 10.3389/fphar.2022.859516
Lysosomal storage diseases (LSDs) are a group of approximately 50 genetic disorders caused by mutations in genes coding enzymes that are involved in cell degradation and transferring lipids and other macromolecules. Accumulation of lipids and other macromolecules in lysosomes leads to the destruction of affected cells. Although the clinical manifestations of different LSDs vary greatly, more than half of LSDs have symptoms of central nervous system neurodegeneration, and within each disorder there is a considerable variation, ranging from severe, infantile-onset forms to attenuated adult-onset disease, sometimes with distinct clinical features. To date, treatment options for this group of diseases remain limited, which highlights the need for further development of innovative therapeutic approaches, that can not only improve the patients' quality of life, but also provide full recovery for them. In many LSDs stem cellbased therapy showed promising results in preclinical researches. This review discusses using mesenchymal stem cells for different LSDs therapy and other neurodegenerative diseases and their possible limitations.

Keywords: lysosomal storage diseases, mesenchymal stem cells, neurodegenerative diseases, cell therapy, mesenchymal stem cell transplantation, clinical trials

\section{INTRODUCTION}

Lysosomal storage diseases (LSDs) are a group of approximately 50 genetic disorders caused by mutations in genes coding enzymes that are involved in cell degradation and transferring lipids and other macromolecules. Due to the accumulation of non-degraded macromolecules in lysosomes, LSDs present with different clinical symptoms (Maegawa 2019; Edelmann and Maegawa 2020). This group of diseases is rare in general but, altogether, their incidence ranges from 1 in 2,315 to 7,700 live-births (Meikle et al., 1999). Most LSDs affect the nervous system and are usually characterized by progressive neurodegeneration accompanied with delayed motor and cognitive functions (Maegawa 2019). All LSDs are inherited as autosomal recessive traits with the exception of Danon, Fabry and Hunter diseases (mucopolysaccharidosis type II), which are X-linked disorders (Wraith, 2002). Within each disorder there is a considerable variation, ranging from severe, infantile-onset forms to attenuated adult-onset disease, sometimes with distinct clinical features. In general, the earlier the onset, the more rapid the 


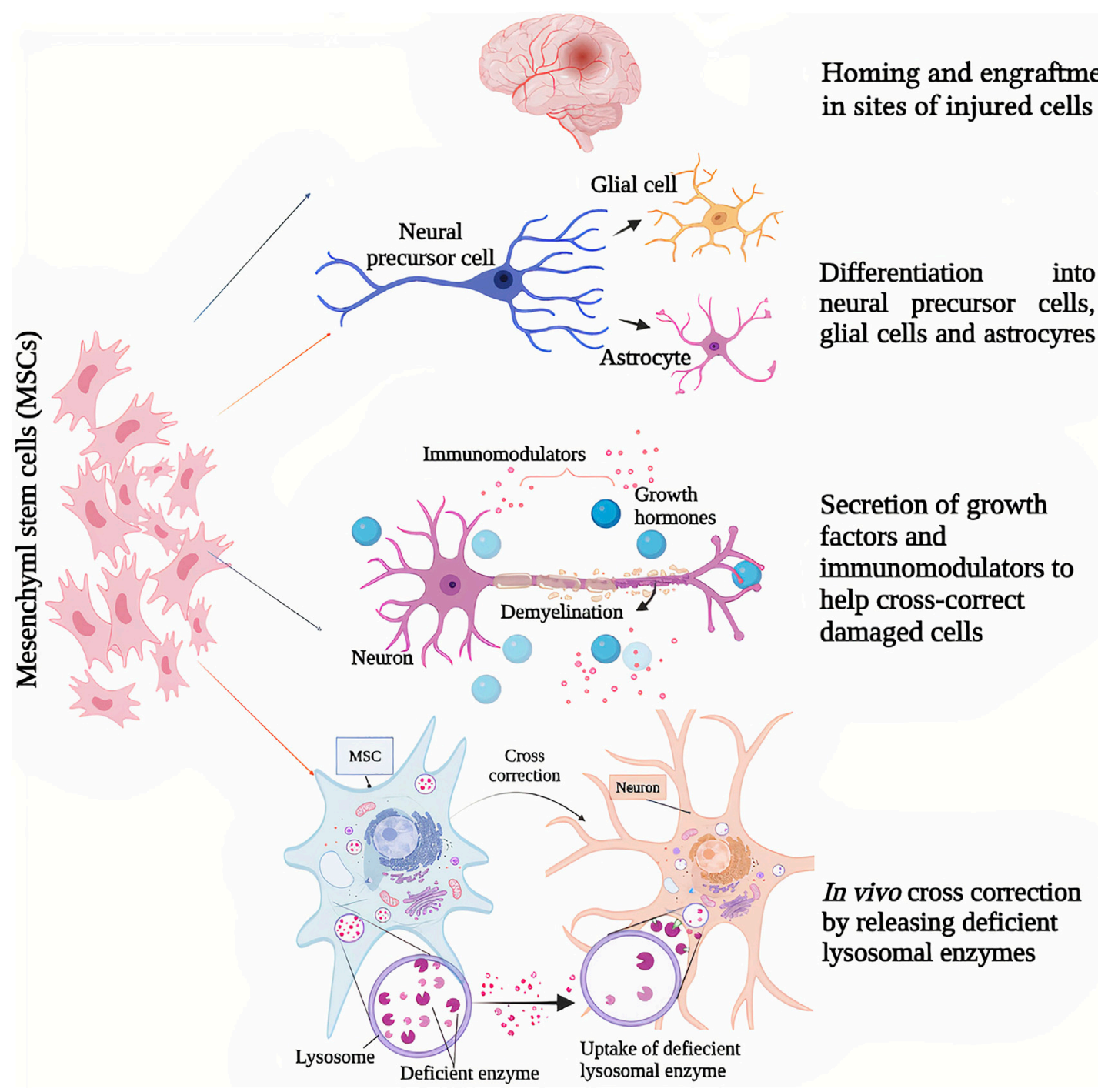

FIGURE 1 | Mesenchymal stem cells' (MSCs) mechanisms of action as potential therapeutic strategies for lysosomal storage diseases and other neurodegenerative diseases; (1) Homing and engraftment in sites of injured cells, (2) differentiation into neural precursor cells, glial cells and astrocytes, (3) secretion of growth factors and neuromodulators to help cross correct damaged cells, (4) in vivo cross correction by releasing deficient lysosomal enzymes.

disease progression, variation can be also secondary to the residual activity of the metabolic pathway involved in each disease (Winchester et al., 2000; Kolodny 2003). LSDs can be classified according to the type of material that is stored. Major categories include sphingolipidoses, mucopolysaccharidoses, and glycogenosis (Bruce A. Fenderson 2009). Over the past several years the number of treatment approaches for patients with LSDs, like enzyme replacement therapy, substrate reduction therapy, hematopoietic stem cell transplantation and gene therapy has rapidly increased, but despite the remarkable advances, efficacy of most of these therapies is still limited, due to different obstacles (Beck 2018; Edward H.; Schuchman and Wassrstein, 2018; Solovyeva et al., 2018). The search for effective and safe therapy approaches for these diseases is of great interest. This review presents an overview of in vivo researches aimed at studying the effect of mesenchymal stem cell (MSCs) transplantation in LSDs and some neurodegenerative diseases.

\section{STEM CELL-BASED THERAPEUTIC APPROACHES FOR LSDS}

The progressive nature of LSDs and limited efficacy of available treatments highlighted the need for further development of innovative therapeutic approaches, and for many LSDs stem cell-based therapy showed promising results in preclinical researches (Scruggs et al., 2012). MSCs are progenitor multipotent adult stem cells that can be derived from several tissues, like umbilical cord, bone marrow or fat tissue. MSCs can 
TABLE 1 | Therapies of LSDs and some neurodegenerative diseases using MSCs.

$\begin{array}{lll}\text { Disease } \quad \text { Study subject } & \begin{array}{l}\text { MSCs dosage, route } \\ \text { of administration and } \\ \text { duration of therapy }\end{array} & \text { Therapy results }\end{array}$

\begin{tabular}{|c|c|c|c|c|}
\hline \multirow[t]{2}{*}{$\begin{array}{l}\text { Krabbe } \\
\text { disease }\end{array}$} & $\begin{array}{l}\text { Twitcher mouse } \\
\text { model }\end{array}$ & $\begin{array}{l}1 \times 10^{5} \text { cells in } 2 \mu l \\
\text { Intracerebral injection } \\
35 \text { days }\end{array}$ & $\begin{array}{l}\text { Anatomical integration, with no tumor formation. } \\
\text { Xenografts remained viable in both normal and } \\
\text { twitcher mouse brain, exhibiting differentiation } \\
\text { into astrocytes, neurons and oligodendrocytes }\end{array}$ & $\begin{array}{l}\text { Croitoru-Lamoury et al. } \\
\text { (2006) }\end{array}$ \\
\hline & & $\begin{array}{l}20,000 \text { cells in } 1 \mu \text { l per hemisphere } \\
\text { Intraventricular injections } \\
40 \text { days }\end{array}$ & $\begin{array}{l}\text { Moderate improvements in life expectancy and } \\
\text { motor function. Decrease in markers of } \\
\text { inflammation, macrophage infiltration, and } \\
\text { microglial activation. Decelerated deterioration in } \\
\text { the twitcher brain }\end{array}$ & Ripoll et al. (2011) \\
\hline
\end{tabular}

\begin{tabular}{ll}
\hline MLD Patients with MLD $\quad 2-10 \times 10^{6}$ cells $/ \mathrm{kg}$ \\
& Intravenous injection \\
& 24 months \\
& $5 \times 10^{6} \mathrm{CD} 34^{+}$cells $/ \mathrm{kg}$ followed by the infusion \\
& of $1 \times 10^{6}$ cells $/ \mathrm{kg}$ of MSCs \\
& 40 months
\end{tabular}

Well tolerance and no toxicity of MSCs infusion. Koç et al. (1999)

Clear evidence of improvement of nerve conduction velocity in $4 / 6$ patients

Stabilization of all previous neurological manifestations with no further deterioration. ArylSulfatase-A levels increased to normal values 16 months after transplantation

\begin{tabular}{|c|c|c|}
\hline \multirow[t]{2}{*}{ NP } & $\begin{array}{l}\mathrm{BALB} / \mathrm{c} n p c^{\text {nih }}(\mathrm{NP}-\mathrm{C}) \\
\text { mice }\end{array}$ & $\begin{array}{l}0.5 \times 10^{6} \text { cells in } 3 \mu \text { l } \\
\text { Intracerebral injection } \\
4 \text { weeks } \\
1 \times 10^{5} \text { cells in } 3 \mu \text { l } \\
\text { Intracerebral injection } \\
1 \text { week }\end{array}$ \\
\hline & & $\begin{array}{l}\text { Dose unidentified } \\
\text { Intracerebral transplantation } \\
4 \text { weeks } \\
1 \times 10^{6} \text { cells in } 3 \mu l \\
\text { Intracerebral injection } \\
1 \text { week }\end{array}$ \\
\hline
\end{tabular}

The transplanted cells infused with Purkinje neurons resulting in preventing their loss

Reduction of sphingosine accumulations in mutant Purkinje neurons. Transplanted cells also promoted survival of neurons and decreased neuronal apoptosis

Decreased inflammatory response as a result of Bae et al. (2005b) suppression of astro/microglial activation by transplanted MSCs

Promoted survival of Purkinje neuron, inhibition Lee et al. (2010b) of cholesterol accumulation or cerebellar apoptotic cell death

$\begin{array}{ll}\text { MPS VII or Sly MPS VII mice } & 1 \times 10^{4} \text { cells in } 2 \mu \mathrm{l} \\ \text { syndrome } & \text { Intrastromal injection } \\ & \text { Three different time frames for different groups of } \\ & \text { animals: } 10,6 \text { and } 2 \text { weeks, respectively }\end{array}$
Catabolism of GAGs accumulated in the cornea Coulson-Thomas, Caterson, and Kao (2013)

\begin{tabular}{|c|c|c|}
\hline Fabry disease & Fabry ko mice & $\begin{array}{l}5 \times 10^{6} \text { cells } \\
\text { Bilateral injection into thigh muscles } \\
4 \text { weeks }\end{array}$ \\
\hline \multirow[t]{2}{*}{ PD } & Wistar rats & $\begin{array}{l}30 \times 10^{3} \text { in } 3 \mu \mathrm{l} \\
\text { Intracerebral injection } \\
8 \text { weeks }\end{array}$ \\
\hline & Sprague-Dawley rats & $\begin{array}{l}23,000 \text { cells in } 8 \mu \mathrm{l} \text { and } 1,80,000 \text { cells in } 8 \mu \mathrm{l} \text { in } \\
\text { two groups of rats } \\
\text { Intracerebral transplantation } \\
4 \text { weeks }\end{array}$ \\
\hline
\end{tabular}

Reduction in lipid accumulation, delivering the Campbell et al. (2002) deficient enzyme to different organs

Improvement in motor functions, increasing in Mostafavi et al. (2019) cells expressing tyrosine hydroxylase, which catalyzes the formation of L-dopa Increase of neuroblast migration in the lesioned Cova et al. (2010) striatum, with multiple signs of MSCs potentials in promoting reparative mechanisms

ALS Patients with ALS In phase 1 and 2 of the trial: Intramuscular (IM) injections at 24 separate sites $\left(1 \times 10^{6}\right.$ cells $/$ site $)$ or intrathecal (IT) administration of $1 \times 10^{6} / \mathrm{kg}$ Indications of possible clinical improvement following transplantation, as $87 \%$ of the patients were found to be responders according to 
TABLE 1 | (Continued) Therapies of LSDs and some neurodegenerative diseases using MSCs.

\begin{tabular}{|c|c|c|c|c|}
\hline Disease & Study subject & $\begin{array}{l}\text { MSCs dosage, route } \\
\text { of administration and } \\
\text { duration of therapy }\end{array}$ & Therapy results & References \\
\hline & & $\begin{array}{l}\text { In phase } 2 \mathrm{a} \\
\text { Both IT and IM administration in } 3 \text { dosing } \\
\text { cohorts } \\
\text { (Low dose: } 1 \times 10^{6} \text { cells } / \mathrm{kg} \text { IT and } 24 \times 10^{6} \text { cells } \\
\text { IM; mid-dose } \\
1.5 \times 10^{6} \mathrm{cells} / \mathrm{kg} \text { IT and } 36 \times 10^{6} \text { cells IM; and } \\
\text { high dose: } 2 \times 10^{6} \text { cells } / \mathrm{kg} \text { IT and } 48 \times 10^{6} \\
\text { cells IM) } \\
3 \text { months }\end{array}$ & $\begin{array}{l}\text { different clinical parameters like ALS Functional } \\
\text { Rating Scale-Revised or forced vital capacity }\end{array}$ & \\
\hline \multirow[t]{3}{*}{ MS } & Patients with MS & $\begin{array}{l}\text { Single IV infusion of } 1-2 \times 10^{6} / \mathrm{Kg} \text { body weight } \\
\text { BMSCs ( } 6 \text { months follow up) }\end{array}$ & $\begin{array}{l}\text { Well-tolerated cell infusion, no treatment-related } \\
\text { serious adverse events, or evidence of disease } \\
\text { activation were found after } 6 \text { months }\end{array}$ & Cohen et al. (2018) \\
\hline & & $\begin{array}{l}140 \times 10^{6} \text { UCBSCs intravenously over seven } \\
\text { visits }\left(20 \times 10^{6} \text { UCBSCs/day) separated by }\right. \\
1-4 \text { days }\end{array}$ & $\begin{array}{l}\text { UCBSCs transplantation was safe and feasible. } \\
\text { No serious adverse events were recorded in } \\
\text { patients. Improvement of symptoms was found } \\
1 \text { month after transplantation, and in some cases } \\
\text { also after } 1 \text { year. Recorded improvements } \\
\text { included expanded disability status scale (EDSS) } \\
\text { scores, bladder, bowel, and sexual dysfunctions, } \\
\text { improvement in walk times, general perspective } \\
\text { of a positive health change and improved quality } \\
\text { of life. } 15 \text { out of } 18 \text { patients showed inactive } \\
\text { lesions in the brain and the cervical spinal cord } \\
\text { after } 1 \text { year, and one patient showed close-to a } \\
\text { complete brain plaques resolution }\end{array}$ & Riordan et al. (2018) \\
\hline & & $\begin{array}{l}\text { Four infusions } \\
\text { Day 0: } 40 \mathrm{ml} \text { of UCBSCs }\left(4 \times 10^{7} \text { cells) infused }\right. \\
\text { intravenously } \\
\text { Days } 7,14 \text { and } 21 \text {, respectively: } 20 \mathrm{ml} \text { UCBSCs } \\
\left(2 \times 10^{7} \text { cells) intravenously injected combined }\right. \\
\text { with } 1 \mathrm{ml}\left(2 \times 10^{7} \text { cells) intrathecally injected }\right.\end{array}$ & $\begin{array}{l}\text { No severe adverse events were recorded during } \\
10 \text {-year follow-up, and combined administration } \\
\text { was found to be safe and feasible, but also } \\
\text { needed to be confirmed by future clinical trials in } \\
\text { a larger cohort }\end{array}$ & Lu et al. (2020) \\
\hline \multirow[t]{2}{*}{$H D$} & $\begin{array}{l}\text { Transgenic HD mice } \\
\text { of the } R 6 / 2 \text { line }\end{array}$ & $\begin{array}{l}5 \times 10^{5} \text { cells in } 2 \mu l \\
\text { Intracerebral injection } \\
12.5 \text { weeks }\end{array}$ & $\begin{array}{l}\text { Significantly slowed striatal degeneration and } \\
\text { behavioral impairment }\end{array}$ & Lee Soon-Tae et al. (2009) \\
\hline & $\begin{array}{l}\text { C57/B6 and R6/2-J2 } \\
\text { mice }\end{array}$ & $\begin{array}{l}3 \times 10^{6} \text { cells } \\
\text { Unilateral intrastriatal injection } \\
16 \text { weeks }\end{array}$ & $\begin{array}{l}\text { Significant decrease of motor impairment. An } \\
\text { increase in survival rate, as the transplanted } \\
\text { MSCs were found to induce neural proliferation in } \\
\text { the lesioned regions of the brain, and also the } \\
\text { migration of microglia and neuroblasts to those } \\
\text { regions }\end{array}$ & Lin et al. (2011) \\
\hline
\end{tabular}

self-renew with the capacity to differentiate into multilineages: mesodermal (such as chondrocytes, osteocytes and adipocytes), ectodermal (neurocytes) and endodermal lineages (hepatocytes) making them a promising candidate for restoration of damaged tissue (Ullah et al., 2015; Chulpanova et al., 2021). Furthermore, MSCs are not only accessible for harvesting in clinical settings, but also can be easily grown in cultures, and are known for their ability to self-renew, express various lysosomal enzymes, modify immune reactions, be transduced by a variety of vectors and not to provoke an immune response (Scruggs et al., 2012; Ebrahim et al., 2020).

Genetic modification of MSCs by transduction using recombinant virus vectors (as lentiviral or adeno-associated viral vectors) has allowed to use them for LSDs therapy to overexpress the inadequate or defective lysosomal enzyme in affected cells; or in some cases, even non-modified stem cells can produce sufficient amounts of endogenous lysosomal enzyme to make a cross-correction in LSD animal models (Hodges and Cheng 2006; Scruggs et al., 2012) (Figure 1). Table 1 provides details of existing in vivo and clinical studies on the efficacy of MSCs in LSDs and several neurodegenerative diseases.

\section{SPECIFIC LSDS AND MSC THERAPY}

\section{Krabbe Disease}

Krabbe disease (or globoid cell leukodystrophy; OMIM \#245200) is an autosomal recessive neurodegenerative disorder that results from deficiency of the lysosomal enzyme galactosylceramidase. The disease has a prevalence of one in 100,000 births, and 
presents as demyelination of the central (CNS) and peripheral (PNS) nervous systems resulting from accumulation of partially metabolized galactocerebroside, with associated morbidity and mortality (Pastores 2009; Won et al., 2016; Pavuluri et al., 2017).

The twitcher mouse model is an authentic model of human Krabbe disease that developed through spontaneous mutation of the gene encoding galactosylceramidase at the Jackson Laboratory in 1976 (Kobayashi et al., 1980) this model presents biochemical and histopathological symptoms that are similar to the human form of Krabbe disease such as loss of oligodendrocytes or demyelination (Suzuki and Suzuki 1995; Ripoll et al., 2011). A study by Croitoru-Lamoury et al. (2006) showed that transplantation of MSCs in the twitcher mouse model of Krabbe disease led to anatomical integration, with no tumor formation, and according to the study; xenografts remained viable in both normal and twitcher mouse brain exhibiting differentiation into astrocytes, neurons and oligodendrocytes. Another study by Ripoll et al. (2011) evaluated the effect of intracerebroventricular administration of MSCs derived either from bone marrow (BMSCs) or adipose tissue (ADSCs) on Krabbe disease pathology. The obtained data in this study indicate that MSCs are potent inhibitors of inflammation processes associated with the disease progression, and that they may offer potential benefits as candidates for in vivo treatment approaches by reducing inflammation levels.

\section{Metachromatic Leukodystrophy (MLD)}

MLD is an autosomal recessive demyelinating leukodystrophy belonging to LSDs, and caused by a deficiency of the lysosomal enzyme arylsulfatase A (ARSA), which is responsible for sulfatides degradation. Less commonly, the disease can be caused by deficiency of sphingolipid B activator protein (SapB), that activates ARSA enzyme and allows its binding to substrate (Shaimardanova et al., 2020). High concentrations of sulfatides accumulating in the white matter of nervous system result in demyelination of PNS and CNS, which causes symptoms like ataxia, seizures and impairment in both motor and cognitive functions (Biffi et al., 2008). Currently, there is no specific treatment for MLD, and its therapy is limited to palliative care and symptomatic management (Klein et al., 2006).

A study by Koç et al. (1999) proved that allogeneic transplantation of BMSCs could be effective for MLD treatment in humans. Although the clinical phenotypic correction was different from one patient to another based on the disease stage and patient's age upon transplantation; but enzymatic activity was found to be higher than expected after transplantation. The study suggested also that MSCs represent candidates for corrective tissue therapy for such diseases as they can differentiate into several cell lineages, and their transplantation provides long term engraftment.

Later in 2002, as an improvement for this therapeutic approach using MSCs, Koç et al. (2002) suggested that intravenously infusion of culture-expanded MSCs can provide higher efficacy for MLD treatment. As a result, MSCs infusion was well tolerated, showed no toxicity, and despite the extended ex vivo culture using fetal calf serum-containing media, there have not been any hypersensitivity reactions. Moreover, four out of six MLD patients in the study showed clear evidence of improvement of nerve conduction velocity (NCV), that, according to the researchers, could reflect reversal in the neuropathology that leads to the loss of motor and sensory amplitudes. For further studies, scientists recommended targeted delivery of MSCs, co-infusion of donor MSCs simultaneously with hematopoietic transplantation or conducting multiple infusions to obtain more improved outcomes. And for better understating of NCV improvement mechanism, it was suggested to conduct further neurophysiologic studies before and after MSC therapy both in clinical and preclinical in animal models.

Another case was reported by Meuleman et al. (2008) of a patient who presented with the adult form of MLD and had developed progressive neurological manifestations over 1 year. Infusion of MSCs along with hematopoietic stem-cell transplantation (HSCT) were performed, and several checkups were done over the following 40 months. As a result, the patient showed stabilization of all previous neurological manifestations with no further deterioration, and Aryl-Sulfatase-A levels increased to normal values 16 months after transplantation.

\section{Niemann-Pick Diseases (NP)}

The Niemann-Pick group of disorders is divided into four autosomal recessive types of the disease: $\mathrm{A}$ and $\mathrm{B}$ as acid sphingomyelinase deficiencies, and $\mathrm{C}$ and $\mathrm{D}$ as deficiencies of transport proteins (Vanier 2013). The first two types are classified as lipid storage diseases, that result in progressive accumulation of sphingomyelin either in visceral organs or in the brain (Vanier 1999), while C and D are characterized by cellular cholesterol trafficking defects resulting from mutations in the genes coding transport proteins NPC1 or NPC2, respectively (Vanier 2013).

A study by Bae et al. (2005b) investigated the relationship between neurodegeneration and MSCs fusion with Purkinje cells. According to the study, targeted transplantation of BMSCs prevented the loss of Purkinje neurons in the murine type of Niemann- Pick disease type C, as the transplanted cells infused with Purkinje neurons, which led to the suggestion of a combined therapy of gene delivery via transplanted MSCs that will serve as a vehicle to merge introduced genetic material with Purkinje cells. Later in 2010, Lee et al. (2010b) again described MSCs therapeutic effect mechanism on neuropathology of NP-C disease. It was found in the study, that cerebellum-targeted BMSCs transplantation led to reduction of sphingosine accumulations in mutant Purkinje neurons of murine Niemann-Pick C, transplanted cells also promoted survival of neurons and decreased neuronal apoptosis. Thereby, these obtained data describe how BMSCs have their therapeutic effect of on the neuropathology of NP-C disease.

Another factor that is thought to play a key role in neurodegenerative pathogenesis, is glial activation (Baudry et al., 2003), and according to a study by Bae et al. (2005a) MSCs are capable of decreasing inflammatory response in the murine form of NP diseases as they can suppress this astro/ microglial activation which again makes MSCs a therapeutic tool candidate for NP disease and other degenerative disorders that 
have similar pathologies. Lee et al. (2010a) also supported this hypothesis in a study in 2010 using human umbilical cord blood derived MSCs (UCBSCs) transplantations instead of BMSCs in mice models of NP-C disease, which was also proved to have the ability to promote survival of Purkinje neuron, inhibit cholesterol accumulation or cerebellar apoptotic cell death and to be considered as a therapeutic candidate for neurodegenerative diseases.

\section{Mucopolysaccharidoses VII (MPS VII) or Sly Syndrome}

MPS VII, also known as Sly syndrome, is an autosomal recessive disorder, belonging to the group of LSDs, and one of the rarest types of mucopolysaccharidosis, with an estimated incidence rate of 1 in 250,000 newborns around the world (Muenzer 2011; Montaño et al., 2016). The disease is caused by deficiency in enzyme's $\beta$-glucuronidase activity, which is usually responsible for glycosaminoglycans (GAGs) degradation (Sly et al., 1973). GAGs accumulation leads later to cellular and organ dysfunction. The clinical presentation of this disease differs widely between patients, with some general manifestations like cognitive impairment, skeletal dysplasia, heart valve abnormalities corneal clouding, developmental delay and hepatosplenomegaly (Coulson-Thomas et al., 2013; Montaño et al., 2016). Therefore, as a result of the disease rareness and its wide spectrum of symptoms; to date there is still no effective treatment regimen for it.

A study by Coulson-Thomas et al. (2013) hypothesized that intrastromally injection of UCBSCs into cornea could help in GAGs degradation and treating corneal defects in the murine type of Sly syndrome. As a result of the study; transplanted MSCs enabled catabolizing the accumulated in cornea GAGs, suggesting that this approach could be applied to treat corneal defects in the human type of disease.

\section{Fabry Disease}

An X-linked recessive disease and the only known X-linked sphingolipid storage disease, characterized by deficiency in the lysosomal enzyme $\alpha$ - Galactosidase A ( $\alpha$-Gal A), that leads to systemic accumulation of globotrioasylceramide (GL-3) and related glycosphingolipids, causing cardiac, cerebrovascular, and even end-stage renal disease depending on type of affected cells (endothelial, cardiac, renal etc.). Disease frequency ranges between $1 / 40,000$ and $1 / 60,000$ in men, while in heterozygous women severity differs as a result of uneven inactivation of chromosome X (Susan E. Campbell et al., 2002; Desnick et al., 2003; Masson et al., 2004).

In 1997 a-Galactosidase A deficient mice were developed as an animal model of Fabry disease that can have similar-to-humans symptoms. Later, a study by Susan E. Campbell et al. (2002) investigated the possibility to correct genetic defect in Fabry disease through bilateral injection of genetically modified human MSCs into thigh muscles of $a-G a l$ A knock out mice. As a result, $a$-Gal A-hMSCs were able to reduce lipid accumulation in treated mice and to deliver the deficient enzyme to different organs.

\section{USING MSCS IN THE TREATMENT OF OTHER NEURODEGENERATIVE DISEASES}

\section{Parkinson's Disease (PD)}

$\mathrm{PD}$ is a neurodegenerative disorder, that affects motor system with signs and symptoms that can be different from one patient to another. In general, it is characterized by tremors, bradykinesia, rigid muscles, loss of automatic movements and speech changes (Lang and Lozano 1998). The Key pathology of PD is loss of dopaminergic neurons, which can be linked to genetic or environmental factors. Currently, the main treatment for PD is drug therapy, which can improve only motor symptoms (Sulzer et al., 2017; Tang et al., 2020) as for nonmotor symptoms, they still cannot be improved by drugs.

A study by Mostafavi et al. (2019) evaluated using MSCs in rat model of PD, where green fluorescent protein (GFP)-labeled MSCs were transplanted in brains of rats (in the striatum specifically). The study results showed an improvement in motor functions of PD rats after MSCs transplantation and an increasing in cells expressing tyrosine hydroxylase, which catalyzes the formation of L-dopa.

A similar study by Cova et al. (2010) showed also that transplanting human MSCs in rat model of PD resulted in increase of neuroblast migration in the lesioned striatum of transplanted rats with multiple signs of MSCs potentials in promoting reparative mechanisms for PD treatment.

\section{Alzheimer's Disease (AD)}

$\mathrm{AD}$ is also a neurodegenerative disease and the most common type of dementia. The disease presents with progressive declining of behavioral and cognitive functions such as language, memory, comprehension, attention, judgment and reasoning (Kumar et al., 2021). AD's pathogenesis has been linked to amyloid $\beta$ plaques $(\mathrm{A} \beta)$ aggregations in specific areas of the human brain (Tiwari et al., 2019). To this date there is still no effective therapeutic or prophylactic approach for this disease.

A study by Lee Jong Kil et al. (2009) tested the effectiveness of using BMSCs as a therapeutic agent in an acutely induced AD animal model. The obtained data showed significant reduction in $\mathrm{A} \beta$ levels following intracerebral transplantation of BMSCs into the animals' brains. Another study by Jiao et al. (2016) studied the potential therapeutic effect of intravenously injection of human placenta amniotic membrane-derived mesenchymal stem cells (hAMSCs) into AD transgenic mice. Following the injection, hAMSCs transplantation was found to be effective at improving spatial learning ability and memory function in the mice, which may be an indicator that hAMSCs could play a preventive or therapeutic role for $\mathrm{AD}$.

Ma et al. (2013) also showed in their study that intracerebral transplantation of ADSCs in AD mice could modify microglial activation, alleviate the disease symptoms and cognitive regression, which again suggests using MSCs for AD therapy.

\section{Amyotrophic Lateral Sclerosis (ALS)}

ALS is another neurodegenerative disease affecting the motor system. It starts with focal muscle weakness and stiffness, that 
progresses relentlessly to different muscles in different body regions, leaving the patient with a survival median of 3 years following the first symptom onset (Masrori et al., 2020). ALS occurrence has been linked to different factors including genetic factors, mitochondrial diseases and oxidative stress (Blasco et al., 2014). This disease is still incurable despite the high number of clinical trials for potential therapies, that were all proven to be negative (Cipollina et al., 2020).

A clinical trial by Petrou et al. (2016) investigated effectiveness and safety of intrathecal and intramuscular MSCs transplantation in ALS patients. Injected MSCs were induced to secrete neurotrophic factors. The trial results showed indications of possible clinical improvement following the transplantation, as $87 \%$ of the patients enrolled in the trials were found to be responders according to different clinical parameters like ALS Functional Rating Scale-Revised or forced vital capacity.

\section{Multiple Sclerosis (MS)}

MS is a chronic, inflammatory disease of CNS, in which focal lymphocytic infiltration results in axonal damage and demyelination (Compston and Coles 2008). The disease is characterized in general by heterogeneity in symptoms, disease course, and outcomes due to the different involvement of motor, sensory, visual and autonomic systems. Optic neuritis, Uhthoff's phenomenon (transient worsening of neurological symptoms with a rise in body temperature) and Lhermitte's phenomenon (an electric shock-like condition, usually felt down the spine or limbs upon neck flexion) are characteristic of MS. (Doshi and Chataway 2016; Klineova and Lublin 2018).

MS is considered to be an autoimmune disease mediated by $\mathrm{T}$ helper (Th) 1 and Th17 cells. Primary contact with an antigen leads to production of proinflammatory cytokines, which results in further Th cell up-regulation and eventually destruction of the blood-brain barrier (BBB), leading to Th cells migration into CNS (Klineova and Lublin 2018).

Therapeutic approaches of MS aim to treat acute attacks, improve symptoms and to stabilize, delay or slightly improve disability, which highlighted the need for new therapeutic approaches (Hauser and Cree 2020). To date, twenty-nine clinical trials worldwide were registered to evaluate the safety of MSCs transplantation in MS patients (Gugliandolo et al., 2020).

A phase 1 clinical trial, conducted by Cohen et al. (2018) proved the viability and safety of autologous BMSCs intravenous transplantation in MS patients. The trial's results showed that cell infusion was well-tolerated, and at a 6-month follow-up there were no treatment-related severe or serious adverse events, or evidence of disease activation.

Riordan et al. (2018) also evaluated the efficacy of intravenous administration of UCBSCs for MS treatment in their open-label, single-arm, single-center phase $1 / 2$ study. Obtained results showed that UCBSCs transplantation was safe and feasible. No serious adverse events were recorded in patients. Improvement of symptoms was found 1 month after transplantation, and in some cases also after 1 year. Recorded improvements included expanded disability status scale (EDSS) scores, bladder, bowel, and sexual dysfunctions, improvement in walk times, general perspective of a positive health change and improved quality of life. 15 out of 18 patients showed inactive lesions in the brain and the cervical spinal cord after 1 year, and one patient showed closeto a complete brain plaques resolution (Riordan et al., 2018; Gugliandolo et al., 2020).

Another trial conducted by Lu et al. (2020) evaluated the efficacy of combined intrathecal and intravenous administration of UCBSCs in MS patients. During 10-year follow-up, no severe adverse events were recorded, and combined administration was found to be safe and feasible, but also needed to be confirmed by future clinical trials in a larger cohort.

\section{Huntington's Disease (HD)}

$\mathrm{HD}$ is a late-onset autosomal dominant neurodegenerative disease characterized by motor impairment symptoms like involuntary choreatic movements, dystonia and impaired balance and posture, along with cognitive decline symptoms such as dementia, learning difficulties and psychiatric disturbances (Roos, 2010; Lo Furno et al., 2018). HD ends ultimately with death after 10-15 years of the first onset (Lo Furno et al., 2018). Currently available therapeutic drugs can only help improving the patient's quality of life by relieving their symptoms.

A study by Lee Soon-Tae et al. (2009) studied the effect of ADSCs transplantation on HD pathology in rat model of the disease. Following intracerebral transplantation, striatal degeneration and behavioral impairment were found to be significantly slowed possibly because of the secreted factors by transplanted MSCs, according to researchers.

Another study by Lin et al. (2011) tested the effect of human BMSCs transplantation on HD mouse model. Obtained results showed a significant decrease of motor impairment and an increase in survival rate, as the transplanted MSCs were found to induce neural proliferation in lesioned regions of the brain, and also the migration of microglia and neuroblasts to those regions.

\section{GENETICALLY MODIFIED MSCS}

In addition to the various potentials MSCs have in treatment or prevention of wide spectrum of diseases, MSCs can be modified to gain more potentials by increasing their survival, retention, migration capacities or growth factor production, principally through genetic engineering (García-Bernal et al., 2021). For example; in therapeutic approaches of neurodegenerative diseases, MSCs can be genetically engineered to overexpress specific neurotrophic factors like nerve growth factor (NGF) or glial cell line-derived neurotrophic factor (Lo Furno et al., 2018). Moradian et al. (2017) showed in their study in 2014 that engineering BMSCs to overexpress neurotrophin-3 (NT3) provided protection of nervous tissues and stimulated MSCs to differentiate (Damasceno et al., 2020). Li et al. (2008) also tested the effect of transplantation of BMSCs genetically engineered to overexpress NGF BMSCs into a rat model of AD. The study findings suggested that applying this approach may play an effective role in $\mathrm{AD}$ treatment, as the transplanted modified BMSCs were able to migrate to target sites, express NGF 
and significantly help improving memory and learning in the rats. In addition, modifying surface receptor expression in MSCs can enhance their homing and migration to the lesioned areas (Nowakowski et al., 2016), and increase their survival and viability rate. A study by Rizvanov et al. (2008) showed that genetically modified hUCBSCs to express human VEGF and mouse neural L1 cell adhesion molecule (L1CAM); were found to be able to successfully migrate into the nervous tissue of mouse model of ALS after transplantation, and survived for over 3 months. Another example of modifying MSCs to enhance their homing features was presented by Liao et al. (2016) in a study aimed to evaluate the targeted delivery of MSCs with triple PSGL1/SLeX/IL-10 engineering in mouse experimental autoimmune encephalomyelitis (EAE), a murine model for human MS (García-Bernal et al., 2021). Modified MSCs were found to have gained significantly enhanced homing features compared to unmodified MSCs. Moreover, IL-10-transfected MSCs showed substantial inhibitory activity on CD4 (+) T lymphocytes proliferation from EAE mice. As for in vivo treatment, modified MSCs evidently exhibited a superior therapeutic efficacy over unmodified ones in EAE mice, having significantly enhanced myelination and reduced lymphocytes infiltration into the white matter of the spinal cord.

MSCs can also be modified to express specific therapeutic genes using viral vectors, that can be introduced to cells by different techniques (Lo Furno et al., 2018). A study by Pollock et al. (2016) investigated the effect of injecting MSCs engineered by lentiviral transduction to overexpress Brainderived neurotrophic factor (BDNF) into a mouse model of $\mathrm{HD}$, as BDNF is known to be a lead candidate for $\mathrm{HD}$ treatment (Zuccato and Cattaneo 2007). Collected data showed significant reduction of atrophy and anxiety in mice after transplantation.

\section{LIMITATIONS OF MSCS CELL MEDIATED THERAPY FOR LSDS}

Although clinical improvements have been documented in patients of different neurodegenerative diseases after using MSCs mediated therapeutic approaches; there still could be many limitations for applying these approaches. For example, in some cases patients need to undergo chronic immunosuppression upon transplantation, which restrains the utility of MSCs in therapy (Meng et al., 2003; Robinson et al., 2005). In addition, invasive intracranial or intrathecal delivery of MSCs may be required sometimes to overcome the blood brain barrier. And even after intracranial or intrathecal injection/ infusion; migration capacity of cells may be limited, which makes it more difficult to achieve even distribution into the targeted area (Hodges and Cheng 2006).

Also, there are several factors that affect the therapeutic approach efficacy, like remaining enzymatic activity, nature of accumulated substrate or the age of patient receiving therapy, all these parametric variations result also in different outcomes after treatment with MSCs. And for some LSDs, overexpression of the deficient enzyme in the brain after MSCs therapy may be toxic or intolerable (Hodges and Cheng 2006; Selden et al., 2008; Scruggs et al., 2012). Moreover, according to Mukhamedshina et al. (2019) there is an important aspect that should be considered upon applying a therapeutic approach using MSCs, which is the donor related heterogeneity of MSCs expression, that could result in a wide variation of therapeutic efficacies. A study by Montzka et al. (2009) aimed to evaluate the capacity of human adult MSCs to differentiate into a neural lineage and to determine the degree of homogeneity between donor samples, found that different donor samples revealed different expression patterns, showing a substantial variation of marker expression. Having found these results, Montzka et al. (2009) also recommended that further studies should consider these inter-donor differences of MSCs prior to treatment.

Furthermore, the relatively small number of LSDs patients around the world limits the ability to design big world-wide clinical trials aimed at studying the best and safest therapeutic for humans.

\section{CONCLUSION}

Despite the rareness of LSDs and limited efficacy of most of their current therapeutic approaches, as early onset and small patient numbers make it difficult for clinical trials to evaluate the effectiveness of various LSD therapy approaches, stem cell therapy in general and MSCs in particular represents promising improvement in the field of regenerative medicine thanks to their pluripotency and migration properties, especially if combined with gene therapy and other supplementary treatments. And although there is still a lot to do about safety and long-term efficacy, with research and efficient clinical studies we can gain more understanding to help improve lives of LSDs patients and overcome the current obstacles on the way of finding the best and safest treatments for them.

\section{AUTHOR CONTRIBUTIONS}

Conceptualization, SI, AS, VS, and AR; writing-original draft preparation, SI, AS, and VS; writing-review and editing, VS, VV, and AR; visualization, SI; supervision, VS and AR. All authors have read and agreed to the published version of the manuscript.

\section{FUNDING}

This work was funded by the subsidy allocated to KFU for the state assignment 0671-2020-0058 in the sphere of scientific activities and by the Kazan Federal University Strategic Academic Leadership Program (PRIORITY-2030).

\section{ACKNOWLEDGMENTS}

We thank the Center for Precision Genome Editing and Genetic Technologies for Biomedicine, IGB RAS for scientific advice on development of gene therapy drugs. 


\section{REFERENCES}

Bae, J. S., Furuya, S., Ahn, S. J., Yi, S. J., Hirabayashi, Y., and Jin, H. K. (2005a). Neuroglial Activation in Niemann-Pick Type C Mice Is Suppressed by Intracerebral Transplantation of Bone Marrow-Derived Mesenchymal Stem Cells. Neurosci. Lett. 381, 234-236. doi:10.1016/j.neulet.2005.02.029

Bae, J. S., Furuya, S., Shinoda, Y., Endo, S., Schuchman, E. H., Hirabayashi, Y., et al. (2005b). Neurodegeneration Augments the Ability of Bone Marrow-Derived Mesenchymal Stem Cells to Fuse with Purkinje Neurons in Niemann-Pick Type C Mice. Hum. Gene Ther. 16, 1006-1011. doi:10.1089/hum.2005.16.1006

Baudry, M., Yao, Y., Simmons, D., Liu, J., and Bi, X. (2003). Postnatal Development of Inflammation in a Murine Model of Niemann-Pick Type C Disease: Immunohistochemical Observations of Microglia and Astroglia. Exp. Neurol. 184, 887-903. doi:10.1016/S0014-4886(03)00345-5

Beck, M. (2018). Treatment Strategies for Lysosomal Storage Disorders. Dev. Med. Child. Neurol. 60, 13-18. doi:10.1111/dmcn.13600

Biffi, A., Lucchini, G., Rovelli, A., and Sessa, M. (2008). Metachromatic Leukodystrophy: an Overview of Current and Prospective Treatments. Bone Marrow Transpl. 42 Suppl 2, S2-S6. doi:10.1038/bmt.2008.275

Blasco, H., Mavel, S., Corcia, P., and Gordon, P. H. (2014). The Glutamate Hypothesis in ALS: Pathophysiology and Drug Development. Curr. Med. Chem. 21, 3551-3575. doi:10.2174/0929867321666140916120118

Campbell, S. E., Kyle Hendricks, J., Murray, G., Alur, R. P., and Vanguri, P. (2002). 'Ex-Vivo Therapy of Fabry Disease Using GeneModified Human Mesenchymal Stem Cells: Efficacy Study in a Knock-Out Mouse Model '. Mol. Ther. 5 (5), S15. doi:10.1016/s1525-0016(16)42869-8

Chulpanova, D. S., Gilazieva, Z. E., Akhmetzyanova, E. R., Kletukhina, S. K., Rizvanov, A. A., and Solovyeva, V. V. (2021). Cytochalasin B-Induced Membrane Vesicles from Human Mesenchymal Stem Cells Overexpressing TRAIL, PTEN and IFN-B1 Can Kill Carcinoma Cancer Cells. Tissue Cell 73, 101664. doi:10.1016/j.tice.2021.101664

Cipollina, G., Davari Serej, A., Di Nolfi, G., Gazzano, A., Marsala, A., Spatafora, M. G., et al. (2020). 'Heterogeneity of Neuroinflammatory Responses in Amyotrophic Lateral Sclerosis: A Challenge or an Opportunity?'. Int. J. Mol. Sci. 21.

Cohen, J. A., Imrey, P. B., Planchon, S. M., Bermel, R. A., Fisher, E., Fox, R. J., et al. (2018). Pilot Trial of Intravenous Autologous Culture-Expanded Mesenchymal Stem Cell Transplantation in Multiple Sclerosis. Mult. Scler. 24, 501-511. doi: $10.1177 / 1352458517703802$

Compston, A., and Coles, A. (2008). Multiple Sclerosis. Lancet 372, 1502-1517. doi:10.1016/S0140-6736(08)61620-7

Coulson-Thomas, V. J., Caterson, B., and Kao, W. W. (2013). Transplantation of Human Umbilical Mesenchymal Stem Cells Cures the Corneal Defects of Mucopolysaccharidosis VII Mice. Stem Cells 31, 2116-2126. doi:10.1002/stem. 1481

Cova, L., Armentero, M. T., Zennaro, E., Calzarossa, C., Bossolasco, P., Busca, G., et al. (2010). Multiple Neurogenic and Neurorescue Effects of Human Mesenchymal Stem Cell after Transplantation in an Experimental Model of Parkinson's Disease. Brain Res. 1311, 12-27. doi:10.1016/j.brainres.2009.11.041

Croitoru-Lamoury, J., Williams, K. R., Lamoury, F. M., Veas, L. A., Ajami, B., Taylor, R. M., et al. (2006). Neural Transplantation of Human MSC and NT2 Cells in the Twitcher Mouse Model. Cytotherapy 8, 445-458. doi:10.1080/ 14653240600879152

Damasceno, P. K. F., de Santana, T. A., Santos, G. C., Orge, I. D., Silva, D. N., Albuquerque, J. F., et al. (2020). Genetic Engineering as a Strategy to Improve the Therapeutic Efficacy of Mesenchymal Stem/Stromal Cells in Regenerative Medicine. Front Cel Dev Biol 8, 737. doi:10.3389/fcell.2020.00737

Desnick, R. J., Brady, R., Barranger, J., Collins, A. J., Germain, D. P., Goldman, M., et al. (2003). Fabry Disease, an Under-recognized Multisystemic Disorder: Expert Recommendations for Diagnosis, Management, and Enzyme Replacement Therapy. Ann. Intern. Med. 138, 338-346. doi:10.7326/00034819-138-4-200302180-00014

Doshi, A., and Chataway, J. (2016). Multiple Sclerosis, a Treatable Disease. Clin. Med. (Lond) 16, s53-s59. doi:10.7861/clinmedicine.16-6-s53

Ebrahim, N., James, V., Rizvanov, A. A., and Mukhamedshina, Y. (2020). Genetic Modification of Mesenchymal Stem Cells for Neurological Disease Therapy:
What Effects Does it Have on Phenotype/Cell Behavior, Determining Their Effectiveness? Mol. Diagn. Ther. 24, 683-702. doi:10.1007/s40291-020-00491-6

Edelmann, M. J., and Maegawa, G. H. B. (2020). CNS-targeting Therapies for Lysosomal Storage Diseases: Current Advances and Challenges. Front. Mol. Biosci. 7, 559804. doi:10.3389/fmolb.2020.559804

Fenderson, Bruce. A. (2009). Pathology Secrets. Mosby.

García-Bernal, D., García-Arranz, M., Yáñez, R. M., Hervás-Salcedo, R., Cortés, A., Fernández-García, M., et al. (2021). The Current Status of Mesenchymal Stromal Cells: Controversies, Unresolved Issues and Some Promising Solutions to Improve Their Therapeutic Efficacy. Front. Cel Dev. Biol. 9, 650664. doi:10.3389/fcell.2021.650664

Gugliandolo, A., Bramanti, P., and Mazzon, E. (2020). 'Mesenchymal Stem Cells in Multiple Sclerosis: Recent Evidence from Pre-clinical to Clinical Studies'. Int. J. Mol. Sci. 21. doi:10.3390/ijms21228662

Hauser, S. L., and Cree, B. A. C. (2020). Treatment of Multiple Sclerosis: A Review. Am. J. Med. 133, 1380-e2. doi:10.1016/j.amjmed.2020.05.049

Hodges, B. L., and Cheng, S. H. (2006). Cell and Gene-Based Therapies for the Lysosomal Storage Diseases. Curr. Gene Ther. 6, 227-241. doi:10.2174/ 156652306776359522

Jiao, H., Shi, K., Zhang, W., Yang, L., Yang, L., Guan, F., et al. (2016). Therapeutic Potential of Human Amniotic Membrane-Derived Mesenchymal Stem Cells in APP Transgenic Mice. Oncol. Lett. 12, 1877-1883. doi:10.3892/ol.2016.4857

Klein, D., Schmandt, T., Muth-Köhne, E., Perez-Bouza, A., Segschneider, M., Gieselmann, V., et al. (2006). Embryonic Stem Cell-Based Reduction of central Nervous System Sulfatide Storage in an Animal Model of Metachromatic Leukodystrophy. Gene Ther. 13, 1686-1695. doi:10.1038/sj.gt.3302834

Klineova, S., and Lublin, F. D. (2018). 'Clinical Course of Multiple Sclerosis'. Cold Spring Harb Perspect. Med. 8, a028928. doi:10.1101/cshperspect.a028928

Kobayashi, T., Yamanaka, T., Jacobs, J. M., Teixeira, F., and Suzuki, K. (1980). The Twitcher Mouse: an Enzymatically Authentic Model of Human Globoid Cell Leukodystrophy (Krabbe Disease). Brain Res. 202, 479-483. doi:10.1016/00068993(80)90159-6

Kolodny, Edwin. H. (2003). Office Practice of Neurology. Churchill Livingstone.

Koç, O. N., Day, J., Nieder, M., Gerson, S. L., Lazarus, H. M., and Krivit, W. (2002). Allogeneic Mesenchymal Stem Cell Infusion for Treatment of Metachromatic Leukodystrophy (MLD) and Hurler Syndrome (MPS-IH). Bone Marrow Transpl. 30, 215-222. doi:10.1038/sj.bmt.1703650

Koç, O. N., Peters, C., Aubourg, P., Raghavan, S., Dyhouse, S., DeGasperi, R., et al. (1999). Bone Marrow-Derived Mesenchymal Stem Cells Remain Host-Derived Despite Successful Hematopoietic Engraftment after Allogeneic Transplantation in Patients with Lysosomal and Peroxisomal Storage Diseases. Exp. Hematol. 27, 1675-1681. doi:10.1016/s0301-472x(99)00101-0

Kumar, A., Sidhu, J., Goyal, A., and Tsao, J. W. (2021). “Alzheimer Disease,” in StatPearls (StatPearls Publishing Copyright (C) 2021 (Treasure Island (FL): StatPearls Publishing LLC.).

Lang, A. E., and Lozano, A. M. (1998). Parkinson's Disease. Second of Two Parts. N. Engl. J. Med. 339, 1130-1143. doi:10.1056/NEJM199810153391607

Lee, H., Bae, J. S., and Jin, H. K. (2010a). Human Umbilical Cord Blood-Derived Mesenchymal Stem Cells Improve Neurological Abnormalities of NiemannPick Type C Mouse by Modulation of Neuroinflammatory Condition. J. Vet. Med. Sci. 72, 709-717. doi:10.1292/jvms.09-0495

Lee, H., Lee, J. K., Min, W. K., Bae, J. H., He, X., Schuchman, E. H., et al. (2010b). Bone Marrow-Derived Mesenchymal Stem Cells Prevent the Loss of NiemannPick Type C Mouse Purkinje Neurons by Correcting Sphingolipid Metabolism and Increasing Sphingosine-1-Phosphate. Stem Cells 28, 821-831. doi:10.1002/ stem.401

Lee, J. K., Jin, H. K., and Bae, J. S. (2009). Bone Marrow-Derived Mesenchymal Stem Cells Reduce Brain Amyloid-Beta Deposition and Accelerate the Activation of Microglia in an Acutely Induced Alzheimer's Disease Mouse Model. Neurosci. Lett. 450, 136-141. doi:10.1016/j.neulet.2008.11.059

Lee, S-T., Chu, K., Jung, K. H., Im, W. S., Park, J. E., Lim, H. C., et al. (2009). Slowed Progression in Models of Huntington Disease by Adipose Stem Cell Transplantation. Ann. Neurol. 66, 671-681. doi:10.1002/ana.21788

Li, L. Y., Li, J. T., Wu, Q. Y., Li, J., Feng, Z. T., Liu, S., et al. (2008). Transplantation of NGF-Gene-Modified Bone Marrow Stromal Cells into a Rat Model of Alzheimer' Disease. J. Mol. Neurosci. 34, 157-163. doi:10.1007/s12031-0079022-x 
Liao, W., Pham, V., Liu, L., Riazifar, M., Pone, E. J., Zhang, S. X., et al. (2016). Mesenchymal Stem Cells Engineered to Express Selectin Ligands and IL-10 Exert Enhanced Therapeutic Efficacy in Murine Experimental Autoimmune Encephalomyelitis. Biomaterials 77, 87-97. doi:10.1016/j.biomaterials.2015. 11.005

Lin, Y. T., Chern, Y., Shen, C. K., Wen, H. L., Chang, Y. C., Li, H., et al. (2011). Human Mesenchymal Stem Cells Prolong Survival and Ameliorate Motor Deficit through Trophic Support in Huntington's Disease Mouse Models. PLoS One 6, e22924. doi:10.1371/journal.pone.0022924

Lo Furno, D., Mannino, G., and Giuffrida, R. (2018). Functional Role of Mesenchymal Stem Cells in the Treatment of Chronic Neurodegenerative Diseases. J. Cel Physiol 233, 3982-3999. doi:10.1002/jcp.26192

Lu, Z., Zhu, L., Liu, Z., Wu, J., Xu, Y., and Zhang, C. J. (2020). IV/IT hUC-MSCs Infusion in RRMS and NMO: A 10-Year Follow-Up Study. Front. Neurol. 11, 967. doi:10.3389/fneur.2020.00967

Ma, T., Gong, K., Ao, Q., Yan, Y., Song, B., Huang, H., et al. (2013). Intracerebral Transplantation of Adipose-Derived Mesenchymal Stem Cells Alternatively Activates Microglia and Ameliorates Neuropathological Deficits in Alzheimer's Disease Mice. Cel Transpl. 22 Suppl 1 (22 Suppl. 1), S113-S126. doi:10.3727/ 096368913 X672181

Maegawa, G. H. B. (2019). Lysosomal Leukodystrophies Lysosomal Storage Diseases Associated with White Matter Abnormalities. J. Child. Neurol. 34, 339-358. doi:10.1177/0883073819828587

Masrori, P., and Van Damme, P. (2020). Amyotrophic Lateral Sclerosis: a Clinical Review. Eur. J. Neurol. 27, 1918-1929. doi:10.1111/ene.14393

Masson, C., Cissé, I., Simon, V., Insalaco, P., and Audran, M. (2004). Fabry Disease: a Review. Jt. Bone Spine 71, 381-383. doi:10.1016/j.jbspin.2003.10.015

Meikle, P. J., Hopwood, J. J., Clague, A. E., and Carey, W. F. (1999). Prevalence of Lysosomal Storage Disorders. Jama 281, 249-254. doi:10.1001/jama.281. 3.249

Meng, X. L., Shen, J. S., Ohashi, T., Maeda, H., Kim, S. U., and Eto, Y. (2003). Brain Transplantation of Genetically Engineered Human Neural Stem Cells Globally Corrects Brain Lesions in the Mucopolysaccharidosis Type VII Mouse. J. Neurosci. Res. 74, 266-277. doi:10.1002/jnr.10764

Meuleman, N., Vanhaelen, G., Tondreau, T., Lewalle, P., Kwan, J., Bennani, J., et al. (2008). Reduced Intensity Conditioning Haematopoietic Stem Cell Transplantation with Mesenchymal Stromal Cells Infusion for the Treatment of Metachromatic Leukodystrophy: a Case Report. Haematologica 93, e11-3. doi:10.3324/haematol.11802

Montaño, A. M., Lock-Hock, N., Steiner, R. D., Graham, B. H., Szlago, M., Greenstein, R., et al. (2016). Clinical Course of Sly Syndrome (Mucopolysaccharidosis Type VII). J. Med. Genet. 53, 403-418. doi:10.1136/ jmedgenet-2015-103322

Montzka, K., Lassonczyk, N., Tschöke, B., Neuss, S., Führmann, T., Franzen, R., et al. (2009). Neural Differentiation Potential of Human Bone Marrow-Derived Mesenchymal Stromal Cells: Misleading Marker Gene Expression. BMC Neurosci. 10, 16. doi:10.1186/1471-2202-10-16

Moradian, H., Keshvari, H., Fasehee, H., Dinarvand, R., and Faghihi, S. (2017). Combining NT3-Overexpressing MSCs and PLGA Microcarriers for Brain Tissue Engineering: A Potential Tool for Treatment of Parkinson's Disease. Mater. Sci. Eng. C Mater. Biol. Appl. 76, 934-943. doi:10.1016/j.msec.2017. 02.178

Mostafavi, H., Ghassemifard, L., Rostami, A., Alipour, M., and Nadri, S. (2019). Trabecular Meshwork Mesenchymal Stem Cell Transplantation Improve Motor Symptoms of Parkinsonian Rat Model. Biologicals 61, 61-67. doi:10. 1016/j.biologicals.2019.06.006

Muenzer, J. (2011). Overview of the Mucopolysaccharidoses. Rheumatology (Oxford) 50 Suppl 5, v4-12. doi:10.1093/rheumatology/ker394

Mukhamedshina, Y., Shulman, I., Ogurcov, S., Kostennikov, A., Zakirova, E., Akhmetzyanova, E., et al. (2019). 'Mesenchymal Stem Cell Therapy for Spinal Cord Contusion: A Comparative Study on Small and Large Animal Models'. Biomolecules 9, 811. doi:10.3390/biom9120811

Nowakowski, A., Walczak, P., Lukomska, B., and Janowski, M. (2016). Genetic Engineering of Mesenchymal Stem Cells to Induce Their Migration and Survival. Stem Cell Int 2016, 4956063. doi:10.1155/2016/4956063

Pastores, G. M. (2009). 'Krabbe Disease: an Overview'. Int. J. Clin. Pharmacol. Ther. 47 (Suppl. 1), S75-S81.
Pavuluri, P., Vadakedath, S., Gundu, R., Uppulety, S., and Kandi, V. (2017). Krabbe Disease: Report of a Rare Lipid Storage and Neurodegenerative Disorder. Cureus 9, e949. doi:10.7759/cureus.949

Petrou, P., Gothelf, Y., Argov, Z., Gotkine, M., Levy, Y. S., Kassis, I., et al. (2016). Safety and Clinical Effects of Mesenchymal Stem Cells Secreting Neurotrophic Factor Transplantation in Patients with Amyotrophic Lateral Sclerosis: Results of Phase 1/2 and 2a Clinical Trials. JAMA Neurol. 73, 337-344. doi:10.1001/ jamaneurol.2015.4321

Pollock, K., Dahlenburg, H., Nelson, H., Fink, K. D., Cary, W., Hendrix, K., et al. (2016). Human Mesenchymal Stem Cells Genetically Engineered to Overexpress Brain-Derived Neurotrophic Factor Improve Outcomes in Huntington's Disease Mouse Models. Mol. Ther. 24, 965-977. doi:10.1038/ mt.2016.12

Riordan, N. H., Morales, I., Fernández, G., Allen, N., Fearnot, N. E., Leckrone, M. E., et al. (2018). Clinical Feasibility of Umbilical Cord Tissue-Derived Mesenchymal Stem Cells in the Treatment of Multiple Sclerosis. J. Transl Med. 16, 57. doi:10.1186/s12967-018-1433-7

Ripoll, C. B., Flaat, M., Klopf-Eiermann, J., Fisher-Perkins, J. M., Trygg, C. B., Scruggs, B. A., et al. (2011). Mesenchymal Lineage Stem Cells Have Pronounced Anti-inflammatory Effects in the Twitcher Mouse Model of Krabbe's Disease. Stem Cells 29, 67-77. doi:10.1002/stem.555

Rizvanov, A. A., Kiyasov, A. P., Gaziziov, I. M., Yilmaz, T. S., Kaligin, M. S., Andreeva, D. I., et al. (2008). Human Umbilical Cord Blood Cells Transfected with VEGF and L(1)CAM Do Not Differentiate into Neurons but Transform into Vascular Endothelial Cells and Secrete Neuro-Trophic Factors to Support Neuro-Genesis-A Novel Approach in Stem Cell Therapy. Neurochem. Int. 53, 389-394. doi:10.1016/j.neuint.2008.09.011

Robinson, A. J., Meedeniya, A. C., Hemsley, K. M., Auclair, D., Crawley, A. C., and Hopwood, J. J. (2005). Survival and Engraftment of Mouse Embryonic Stem Cell-Derived Implants in the guinea Pig Brain. Neurosci. Res. 53, 161-168. doi:10.1016/j.neures.2005.06.010

Roos, R. A. (2010). Huntington's Disease: a Clinical Review. Orphanet J. Rare Dis. 5, 40. doi:10.1186/1750-1172-5-40

Schuchman, E. H., and Wasserstein, M. P. (2018). Hematology. Elsevier.

Scruggs, B. A., Zhang, X., Gimble, J. M., and Bunnell, B. A. (2012). "'Stem CellBased Therapy for Lysosomal Storage Diseases," in Stem Cells and Human Diseases. Editors S. Shankar and R. Srivastava (Dordrecht: Springer).

Selden, N. R., Guillaume, D. J., Steiner, R. D., and Huhn, S. L. (2008). Cellular Therapy for Childhood Neurodegenerative Disease. Part II: Clinical Trial Design and Implementation. Neurosurg. Focus 24, E23. doi:10.3171/FOC/ 2008/24/3-4/E22

Shaimardanova, A. A., Chulpanova, D. S., Solovyeva, V. V., Mullagulova, A. I., Kitaeva, K. V., Allegrucci, C., et al. (2020). Metachromatic Leukodystrophy: Diagnosis, Modeling, and Treatment Approaches. Front. Med. (Lausanne) 7 , 576221. doi:10.3389/fmed.2020.576221

Sly, W. S., Quinton, B. A., McAlister, W. H., and Rimoin, D. L. (1973). Beta Glucuronidase Deficiency: Report of Clinical, Radiologic, and Biochemical Features of a New Mucopolysaccharidosis. J. Pediatr. 82, 249-257. doi:10. 1016/s0022-3476(73)80162-3

Solovyeva, V. V., Shaimardanova, A. A., Chulpanova, D. S., Kitaeva, K. V., Chakrabarti, L., and Rizvanov, A. A. (2018). New Approaches to Tay-Sachs Disease Therapy. Front. Physiol. 9, 1663. doi:10.3389/fphys.2018.01663

Sulzer, D., Alcalay, R. N., Garretti, F., Cote, L., Kanter, E., Agin-Liebes, J., et al. (2017). Erratum: T Cells from Patients with Parkinson's Disease Recognize $\alpha$ synuclein Peptides. Nature 546, 656-661. doi:10.1038/nature23896

Suzuki, K., and Suzuki, K. (1995). The Twitcher Mouse: a Model for Krabbe Disease and for Experimental Therapies. Brain Pathol. 5, 249-258. doi:10.1111/j.17503639.1995.tb00601.x

Tang, X., Wu, C., Li, X., Song, Y., Yao, X., Wu, X., et al. (2020). On the Origin and Continuing Evolution of SARS-CoV-2. Natl. Sci. Rev. 7, 1012-1023. doi:10. 1093/nsr/nwaa036

Tiwari, S., Atluri, V., Kaushik, A., Yndart, A., and Nair, M. (2019). Alzheimer's Disease: Pathogenesis, Diagnostics, and Therapeutics. Int. J. Nanomedicine 14, 5541-5554. doi:10.2147/IJN.S200490

Ullah, I., Subbarao, R. B., and Rho, G. J. (2015). 'Human Mesenchymal Stem Cells Current Trends and Future Prospective'. Biosci. Rep. 35, e00191. doi:10.1042/ BSR20150025 
Vanier, M. T. (2013). 'Niemann-Pick Diseases'. Handb Clin. Neurol. 113, 1717-1721. doi:10.1016/B978-0-444-59565-2.00041-1

Vanier, M. T. (1999). Lipid Changes in Niemann-Pick Disease Type C Brain: Personal Experience and Review of the Literature. Neurochem. Res. 24, 481-489. doi:10.1023/a:1022575511354

Winchester, B., Vellodi, A., and Young, E. (2000). The Molecular Basis of Lysosomal Storage Diseases and Their Treatment. Biochem. Soc. Trans. 28, 150-154. doi:10.1042/bst0280150

Won, J. S., Singh, A. K., and Singh, I. (2016). Biochemical, Cell Biological, Pathological, and Therapeutic Aspects of Krabbe's Disease. J. Neurosci. Res. 94, 990-1006. doi:10.1002/jnr.23873

Wraith, J. E. (2002). Lysosomal Disorders. Semin. Neonatol 7, 75-83. doi:10.1053/ siny.2001.0088

Zuccato, C., and Cattaneo, E. (2007). Role of Brain-Derived Neurotrophic Factor in Huntington's Disease. Prog. Neurobiol. 81, 294-330. doi:10.1016/j.pneurobio. 2007.01.003
Conflict of Interest: The authors declare that the research was conducted in the absence of any commercial or financial relationships that could be construed as a potential conflict of interest.

Publisher's Note: All claims expressed in this article are solely those of the authors and do not necessarily represent those of their affiliated organizations, or those of the publisher, the editors and the reviewers. Any product that may be evaluated in this article, or claim that may be made by its manufacturer, is not guaranteed or endorsed by the publisher.

Copyright $\odot 2022$ Issa, Shaimardanova, Valiullin, Rizvanov and Solovyeva. This is an open-access article distributed under the terms of the Creative Commons Attribution License (CC BY). The use, distribution or reproduction in other forums is permitted, provided the original author(s) and the copyright owner(s) are credited and that the original publication in this journal is cited, in accordance with accepted academic practice. No use, distribution or reproduction is permitted which does not comply with these terms. 